\title{
Performance investigation of multi-level inverter for DFIG during grid autoreclosure operation
}

\author{
Mahrous Ahmed ${ }^{1}$, Mohamed K. Metwaly ${ }^{2}$, Nagy I. Elkalashy ${ }^{3}$ \\ ${ }^{1,2,3}$ Department of Electrical Engineering, College of Engineering, Taif University, KSA \\ ${ }^{1}$ Department of Electrical Engineering, Faculty of Engineering, South Valley University, Egypt \\ ${ }^{2,3}$ Department of Electrical Engineering, Faculty of Engineering, Menoufia University, Egypt
}

\section{Article Info}

Article history:

Received Jul 17, 2018

Revised Oct 30, 2018

Accepted Dec 3, 2018

Keywords:

Arcing fault

Double-circuit transmission line

Doubly-fed induction

generators

Multi-level inverter

Single-pole autoreclosure

ABSTRACT

This paper aims to study the multi-level inverter (MLI) fed the widely used doubly-fed induction generators (DFIG). The new DFIG generator connected to the electrical grid is evaluated during single-pole autoreclosure operation to continue the generator support to the system. The effect of using MLI on the performance of the DFIG system during the dynamic operation of the autoreclosure is studied for the first time and integrating a new MLI during the fault and clearing periods. A dynamic arc model is represented depending on Kizilcay model. Furthermore, the dynamics performance of the DFIG during integration with MLI to improve the performance is studied. The MLI is preferred because of processing high power with high resolution of the voltage waveforms and lower stresses on switches. The MLI enhances the performance of DFIG-based generating system associated with electrical grid system in case of single-pole autoreclosure. The proposed cases of studies are simulated using Matlab/Simulink to evaluate the proposed system performance during the autoreclosure operation for faults in double-circuit transmission systems.
\end{abstract}

Copyright (C) 2019 Institute of Advanced Engineering and Science. All rights reserved.

\section{Corresponding Author:}

Mahrous Ahmed, Department of Electrical Engineering, College of Engineering, Taif University, KSA.

Email: meahmed7@gmail.com

\section{INTRODUCTION}

The Wind energy has obviously become an effective support for the energy sources in electricity generation all over the world. The transmission systems are important to connect between generation units and loads and accordingly facilitate bulk power transmissions. For example, the wind farms generations are delivered to the loads through the transmission systems. Generally, the double-circuit transmission systems are used in order to enhance the transmission system reliability. If one of the circuits is faulted, it is isolated by the protection systems and accordingly, the power is transmitted through the other circuit.

Rcently doubly-fed induction generator (DFIG) is one of the resources of wind energy converted to electric energy. DFIG is the commonly used pattern-based wind turbine because it has small scale converters and its control facility regarding the active and reactive power which is significant regarding the grid integration [1]-[4]. Previously, the generators-based wind turbine farms were out of service from the grid connection when the terminal voltage less than $80 \%$ of the rated value, which is currently not valid because of high breakthrough of wind farms. For regulating the wind farms operation, the grid code requirements were updated by the power system operation [5]-[7]. The worthiest demand in these regulations is that related to the behavior during the fault cases. Through this requirement, the generator immunity should be increased during the fault and stayed connected to the grid for a specific period defined by this rule characteristic, which is called the fault ride through (FRT) or the low voltage ride through (LVRT) characteristic [8], [9]. 
There are several fault classifications in power systems such transient/permanent faults, singlephase/two-phase/three-phase faults, earth/phase faults, and shunt/series faults. When the fault is permanent, the line should be isolated without any reclosing in order to avoid reclosing onto fault. However, when the fault is transient, the line should be isolated and then reclosing after a predetermined time in order to avoid closing onto fault. Most of the faults in the power transmission systems are transient faults where they represent more than $80 \%$. The main feature of these faults is that they are dielectric breakdown through the arc element and accordingly the transient faults can be called arcing faults.

When the arcing faults are detected using the protection system, the input energy to the arc is diminished when the fault current is interrupted. However, there is a time where the arcing medium is deionized where this period is called the secondary arc. The secondary arc period time depends on the surrounding medium such as wind. After the arcing medium is de-ionized, the reclosure can safely reclose without switching onto fault and accordingly it inserts the circuit onto healthy operation. Generally, the reclosing instant depends on detecting the secondary arc extinction instant and the reclosure is adaptively reclosing that is called adaptive reclosure [10]-[17]. Integrating the designed DFIG with the autoreclosure protection system is evaluated in this paper. However, the operation of the single-pole autoreclosure has not integrated with the performance of the grid connected DFIG.

Using multi-level inverters (MLIs) [18], [19] is preferred compared with the conventional two levels $\mathrm{H}$-bridge inverter for many reasons. MLIs are able to process high power at low switching frequency and high output voltage resolution (low total harmonic distortion (THD)). Therefore, MLIs have lower switches stresses with higher efficiency. One more important advantage of the MLIs is the modularity which enable MLIs to operate even if under faulty condition [20], [21]. This is can be done by modifying the control algorithm to bypass the faulty section without changing in the MLI structure.

There are three main MLIs categories (1) neutral point clamped MLI; (2) cascaded dc sources inverter, (3) flying capacitor MLI inverter. MLIs can also be divided into two main categories based on the dc sources available, symmetrical and asymmetrical MLIs. In symmetrical MLI, all dc sources are equal while in asymmetrical MLIs dc sources are not equal. Asymmetrical MLIs are used to generate higher levels compare to the symmetrical MLIs for the same number of switches. The main ratios among dc sources are $1: 2$ and 1:3, and the 1:3 ratio can develop the highest output voltage resolution and thus lowest THD. Recently hybrid MLI is emerged [22]-[24] to reduce the number of MLI' switches used and thus increasing their reliability. Hybrid MLIs have different structure with different dc sources ratio. By looking to the literature review, one can notice that MLIs are rarely incorporated with the DFIG system although they have many types, categories and advantages. This is indicated that MLI integrated with the DFIG system is open for research.

In this paper, a multi-level inverter is integrated with the DFIG instead of the conventional two levels inverters. The performance of multi-level inverter control is evaluated when the wind driven system fed DFIG is subjected to transient ground fault. This research reveals that the wind turbine generator immunity could be capable of supporting the grid through the single-phase autoreclosure. Then, the DFIG during the fault periods in the double-circuit transmission systems and clearing fault is integrated. The double-circuit is considered in this paper due to its enhancement in the grid reliability as the faulted circuit is interrupted using the protection while the healthy circuit continues the power transmission service. This double-circuit interconnection increased the DFIG low voltage ride through capability during the single-pole autoreclosure operation.

\section{SIMULATED SYSTEM}

Figure 1(a) shows the simulated power system containing the $380-\mathrm{kV}$ power grid, double-circuit transmission line, delta/star transformer and wind farm. For the wind farm installation, the wind speed is assumed as $15 \mathrm{~m} / \mathrm{s}$. Although the wind has a dynamic time characteristic, it is considered a fixed value during the fault as the fault event and clearance has electrical time constant that is very low comparing the wind speed time change. The wind farm consisted of six wind generation units where each unit generated 1.5 MW. Further parameters are in the Appendix. The fault case occurred at the middle of one of the circuits as depicted in the figure. This transmission system interconnected between the grid and the wind farm where the grid simulated by a static source behind impedance and power transformer.

Figure 1(b) shows a schematic diagram of the structure of the DFIG. The three-phase wound induction machine is used. Between the rotor and the grid, there are two converters and capacitor where the capacitor voltage is the MLI main stage voltage equal to three times of the auxiliary stage voltage $\left(3 \mathrm{~V}_{\mathrm{dc}}\right)$. The rotor side converter is implemented as a conventional one while the grid side converter is replaced by multi-level converter. When the power direction is from the rotor to grid, this converter operation is multi-

Perfomance investigastion of multi-level inverter for dfig during grid autoreclosure... (Mahrous Ahmed) 
level inverter while it is operated as a rectifier when the power is in the reverse direction through the dc link. Building up the multi-level inverter in the Simulink/Matlab program is discussed as follows.

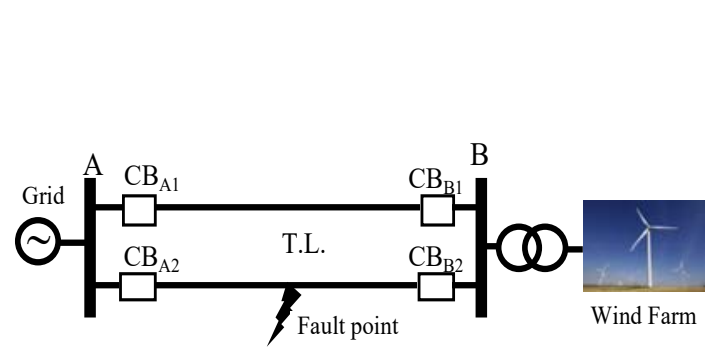

(a) Grid-interconnected wind farm

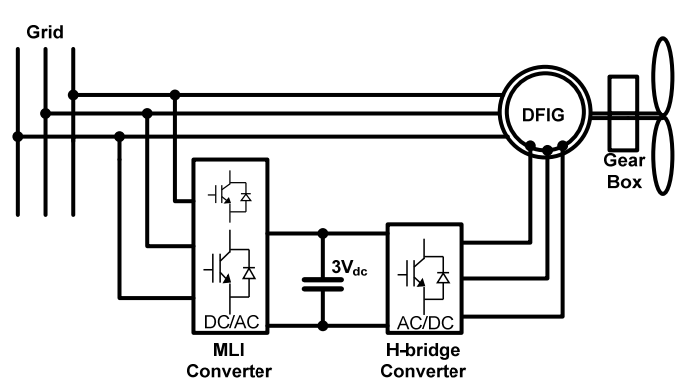

(b) Schematic diagram of the DFIG

Figure 1. Simulated benchmark

The wind farm under study consists of six units connected in parallel, the parameters of one unit based DFIG, converters parameters, and controller parameters are illustrated in Tables 3, 4, and 5. The description of these parameters was reported in [28] where they were designed for two conventional converters of the DFIG and they are exploited for integrating the proposed MLI.

\section{Table 3. Parameters of DFIG}

\begin{tabular}{lcc}
\hline Parameter & Symbol & Value \\
\hline Power & $P$ & $1.5 \mathrm{MW}$ \\
Stator voltage & $\mathrm{V}_{\mathrm{s}}$ & $575 \mathrm{Vrms}$ \\
Rotor voltage & $\mathrm{V}_{\mathrm{r}}$ & $1975 \mathrm{Vrms}$ \\
Stator Frequency & $\mathrm{F}_{\mathrm{s}}$ & $60 \mathrm{~Hz}$ \\
Stator resistance & $\mathrm{R}_{\mathrm{s}}$ & $0.023 \mathrm{p.u}$. \\
Rotor resistance & $\mathrm{R}_{\mathrm{r}}$ & $0.016 \mathrm{p} . \mathrm{u}$. \\
Rotor leakage inductance & $\mathrm{L}_{\mathrm{lr}}$ & $0.16 \mathrm{p} . \mathrm{u}$. \\
Stator leakage inductance & $\mathrm{L}_{\mathrm{ls}}$ & $0.18 \mathrm{p} . \mathrm{u}$. \\
Mutual inductance & $\mathrm{L}_{\mathrm{m}}$ & $2.9 \mathrm{p} . \mathrm{u}$. \\
\hline
\end{tabular}

Table 4. Converters parameters

\begin{tabular}{|c|c|}
\hline Parameter & Value \\
\hline Grid side converter coupling inductor & 0.3 p.u. \\
\hline Grid side converter coupling resistor & 0.003p.u. \\
\hline DC Bus voltage $\left(3 \mathrm{~V}_{\mathrm{dc}}\right)$ & $700 \mathrm{~V}$ \\
\hline DC Bus capacitor & $0.01 \mathrm{~F}$ \\
\hline Line filter capacitor $(\mathrm{Q}=50)(\mathrm{var})$ & $120 \mathrm{e} 3$ \\
\hline \multicolumn{2}{|l|}{ Table 5. Controller parameters } \\
\hline Parameter & Value \\
\hline 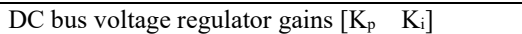 & {$\left[\begin{array}{ll}4 & 400\end{array}\right]$} \\
\hline $\begin{array}{l}\text { Grid-side converter current regulator gains }\left[\mathrm{K}_{\mathrm{p}}\right. \\
\left.\mathrm{K}_{\mathrm{i}}\right]\end{array}$ & {$\left[\begin{array}{ll}0.83 & 5\end{array}\right]$} \\
\hline $\begin{array}{l}\text { Rotor-side converter current regulator gains } \\
{\left[\begin{array}{ll}\mathrm{K}_{\mathrm{p}} & \mathrm{K}_{\mathrm{i}}\end{array}\right]}\end{array}$ & {$[0.6$} \\
\hline Speed regulator gains $\left[\begin{array}{ll}\mathrm{K}_{\mathrm{p}} & \mathrm{K}_{\mathrm{i}}\end{array}\right]$ & {$\left[\begin{array}{ll}1.5 & 0.6\end{array}\right]$} \\
\hline $\mathrm{Q}$ and $\mathrm{V}$ regulator gains [Ki_var $\mathrm{Ki}$ _volt] & {$\left[\begin{array}{ll}1 & 30\end{array}\right]$} \\
\hline
\end{tabular}

\subsection{Mathematical Modeling of Interacted DFIG}

The mathematical model of the DFIG is represented as in [2]. The direct and quadrature axis (dq-axis) representation of the machine voltages equations and flux linkages are as follows.

$$
\begin{array}{lc}
V_{d s}=R_{s} i_{d s}+\frac{d}{d t} \psi_{d s}-\omega_{s} \psi_{q s}, & V_{q s}=R_{s} i_{q s}+\frac{d}{d t} \psi_{q s}+\omega_{s} \psi_{d s} \\
V_{d r}=R_{r} i_{d r}+\frac{d}{d t} \psi_{d r}-\left(\omega_{s}-\omega_{r}\right) \psi_{q r}, & V_{q r}=R_{r} i_{q r}+\frac{d}{d t} \psi_{q r}-\left(\omega_{s}-\omega_{r}\right) \psi_{d r} \\
\psi_{d s}=L_{s} i_{d s}+L_{m} i_{d r}, & \psi_{q s}=L_{s} i_{q s}+L_{m} i_{q r} \\
\psi_{d r}=L_{r} i_{d r}+L_{m} i_{d s}, & \psi_{q r}=L_{r} i_{q r}+L_{m} i_{q s}
\end{array}
$$


where $\omega_{s}$ is the angular stator speed, $\omega_{r}$ is the angular rotor speed, $R_{r}$ and $R_{s}$ are the rotor and stator resistances, respectively. The stator inductance is $L_{s}$, rotor inductance $L_{r}$ and the magnetizing inductance $L_{m}$.

$$
L_{s}=L_{l s}+L_{m}, \quad L_{r}=L_{l r}+L_{m}
$$

where $L_{l s}$ and $L_{l r}$ are the stator and rotor leakage inductances, respectively. The stator active and reactive power components can be described by;

$$
P_{s}=-\frac{3}{2}\left(V_{d s} i_{d s}+V_{q s} i_{q s}\right), \quad Q_{s}=-\frac{3}{2}\left(V_{q s} i_{d s}-V_{d s} i_{q s}\right)
$$

\subsection{Multi-level Inverters Design}

Figure 2 shows the three-phase configuration of the hybrid multi-level inverter topology that can generate nine levels for line-to-line voltage [23], [24]. This inverter is composed of single unit as a main stage, 3 auxiliary units, ' 18 ' switches and ' 4 ' isolated unequal dc voltage sources. The ratio of the dc voltage sources of the auxiliary stage to the main stage is chosen $1 / 3$, therefore this inverter provides high output voltage levels. Therefore, if the main stage has voltage source $3 V_{d c}$, then the auxiliary stage voltage source is $V_{d c}$. The main stage is a conventional two-level three-phase six switch inverter. Each auxiliary cell consists of the well-known 4 switches H-bridge single phase inverter with a single dc source. Each auxiliary cell can generate three levels voltages $-V_{d c}, 0$, and $V_{d c}$. The main stage can generate two levels either $0 \mathrm{~V}$ or $3 V_{d c}$. Therefore, the generated phase voltage to the neutral of the dc source $v_{a N}$ will have five levels, they are 0 , $V_{d c}, 2 V_{d c}, 3 V_{d c}$, and $4 V_{d c}$. Therefore, the load line-to-line voltages can have 9 levels voltages $\left(4 V_{d c}, 3 V_{d c}\right.$, $\left.2 V_{d c}, V_{d c}, 0,-V_{d c},-2 V_{d c},-3 V_{d c},-4 V_{d c},\right)$. Table 1 shows the switching states of this inverter topology. The idea behind chosen this inverter is that, only single dc source can be used for the main stage and the other $3 \mathrm{dc}$ sources for the auxiliary circuits can be generated using a high frequency transformer (HFT) [25].

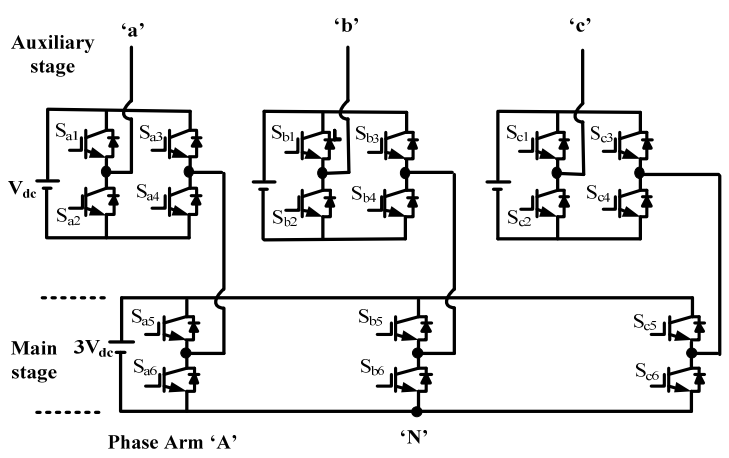

Table 1. Switching States of phase $v_{a N}$

\begin{tabular}{ccccccc}
\hline & \multicolumn{6}{c}{ Switches of arm 'A' } \\
\hline$v_{a N}$ & sa1 & Sa2 & Sa3 & Sa4 & Sa5 & Sa6 \\
$0 \mathrm{~V}_{\mathrm{dc}}$ & 1 & 0 & 1 & 0 & 0 & 1 \\
$1 \mathrm{~V}_{\mathrm{dc}}$ & 1 & 0 & 0 & 1 & 0 & 1 \\
$2 \mathrm{~V}_{\mathrm{dc}}$ & 0 & 1 & 1 & 0 & 1 & 0 \\
$3 \mathrm{~V}_{\mathrm{dc}}$ & 1 & 0 & 0 & 1 & 1 & 0 \\
$4 \mathrm{~V}_{\mathrm{dc}}$ & 1 & 0 & 0 & 1 & 1 & 0 \\
\hline
\end{tabular}

Figure 2. Power circuit of the nine-level line-to-line hybrid MLI

\subsection{Space Vector Control Algorithm of Three-phase Asymmetrical Cascaded MLI}

The inverter output voltages are generated using space vector modulation control scheme. The ac reference voltages are approximated by three nearest switching voltages by the inverter. Therefore, this section presents the well-known space vector modulation (SVM) control algorithm [22]-[24]. Each voltage of $v_{a N}, v_{b N}$ and $v_{c N}$ has five possible states $\left(0, V_{d c}, 2 V_{d c}, 3 V_{d c}, 4 V_{d c}\right)$ as shown in table 1 , thus there are 125 possible states of this inverter generating 61 voltage vectors shown in Figure 3 . These 61 vectors can be divided into four groups based on their magnitude. It is observed from Figure 3 and Table 2 that each vector group located on single hexagon constituting 4 groups.

Perfomance investigastion of multi-level inverter for dfig during grid autoreclosure... (Mahrous Ahmed) 


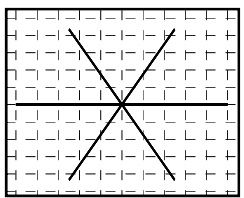

(a). Group 2: $\vec{V}_{1}$ to $\vec{V}_{6}$ with $V_{d c}$ magnitude

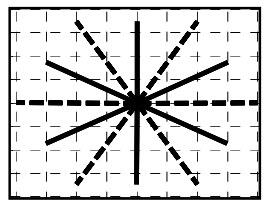

(b). Group 3: vectors $\overrightarrow{\mathrm{V}}_{7}$ to $\overrightarrow{\mathrm{V}}_{18}$ with $\sqrt{3} V_{d c}$ magnitudes (solid) and $2 V_{d c}$ (dash)

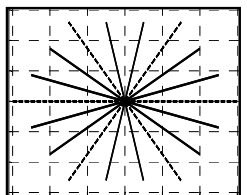

(c). Group 4: $\overrightarrow{\mathrm{V}}_{19}$ to $\overrightarrow{\mathrm{V}}_{36}$ with 2.64V $V_{d c}$ (solid) and $3 V_{d c}$ (dash)

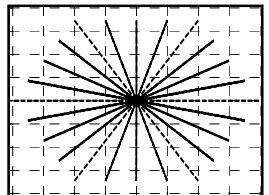

(d). Group 5: $\vec{V}_{37}$ to $\vec{V}_{61}$ with $2.46 V_{d c}$ (solid) and $4 V_{d c}$ (dash)

Figure 3. Voltage vector groups diagram of the five-level 3-phase MLI

Table 2. Groups of space voltage vectors

\begin{tabular}{llc}
\hline Vector name & \multicolumn{1}{c}{ States } & magnitude \\
\hline Group 1: Zero vectors $V_{0}$ & [000], [111], [222], [333] and [444]. & $0 \mathrm{~V}$ \\
Group 2:Small vectors $V_{1} \rightarrow V_{6}$ & Six vectors with 24 states & $V_{d c}$ \\
Group 3: Medium vectors 1 $V_{7} \rightarrow V_{12}$ & Six vectors with 18 states & $\sqrt{3} V_{d c}$ \\
Group 3: Medium vectors 2 $V_{13} \rightarrow V_{18}$ & Six vectors with 18 states & $2 V_{d c}$ \\
Group 4: Medium vectors 3 $V_{19} \rightarrow V_{30}$ & Twelve vectors with 24 states & $2.65 V_{d c}$ \\
Group 4: Medium vectors 4 $V_{31} \rightarrow V_{36}$ & Six vectors with 12 states & $3 V_{d c}$ \\
Group 5: Large vectors 1 $V_{37} \rightarrow V_{42}$ & Six vectors with 6 states & $3.46 V_{d c}$ \\
Group 5: Large vectors 2 $V_{43} \rightarrow V_{54}$ & Twelve vectors with 12 states & $3.61 V_{d c}$ \\
Group 5: Large vectors 3 $V_{55} \rightarrow V_{61}$ & Six vectors with 6 states & $4 V_{d c}$ \\
\hline
\end{tabular}

In this SVM method, the normalized space vector for every switching state states for the three-phase voltages $v_{a N}, v_{b N}$ and $v_{c N}$ with respect to the neutral of the dc bus voltage is defined by;

$$
V_{S V N}=\left(\frac{1}{V_{d c}}\right) *\left(v_{a N}+e^{\frac{j 2 \pi}{3}} v_{b N}+e^{\frac{j 4 \pi}{3}} v_{c N}\right)=V_{S V d}+j V_{S V q}
$$

The magnitude of this normalized vector and its angle can be governed by;

$$
\left\|V_{S V N}\right\|=\sqrt{V_{S V d}^{2}+V_{S V q}^{2}} \quad \text { and } \quad \beta=\tan ^{-1}\left(\frac{V_{S V q}}{V_{S V d}}\right) \quad \text { (four quadrant angle) }
$$

The magnitude of the normalized space vector defines the group of vectors that the space vector lays. These steps of defining the group of vectors are provided below. Once the group of vectors is defined then the angle of the normalized space vector is easily used to locate the normalized vector inside the triangle of the three nearest vectors $\left(V_{0}, V_{1}, V_{2}\right)$. Finally, the switching times $\left(T_{0}, T_{1}, T_{2}\right)$ of the three nearest vectors are accurately defined from;

$$
T_{0} * V_{0}+T_{1} * V_{1}+T_{2} * V_{2}=T * V_{S V N}
$$

where $T=\frac{1}{f_{s}}$ and is the sampling interval. From table 2, the following steps summarize how to implement SVM control algorithm.

- Step 1: If $\left\|V_{S V N}\right\| \leq 0.5$ then $V_{S V N}$ lays in Group 1 (zero voltage vector).

- $\quad$ Step 2: If $0.5<\left\|V_{S V N}\right\| \leq 1.366$ then $V_{S V N}$ lays in Group 2 .

- $\quad$ Step 3: If $1.366<\left\|V_{S V N}\right\| \leq 2.825$ then $V_{S V N}$ lays in Group 3.

- $\quad$ Step 3: If $2.825<\left\|V_{S V N}\right\| \leq 3.23$ then $V_{S V N}$ lays in Group 4.

- $\quad$ Step 5: If $\left\|V_{S V N}\right\| \geq 3.23$ then $V_{S V N}$ lays in Group 5.

\subsection{Arcing Fault Model for Single-pole Autoreclosure}

The single-pole autoreclosure has been incorporated in different power transmission systems as it enhanced the system stability. Several challenges are the motivation of research continuity such as discrimination between transient and permanent faults, secondary arc extinction detection to avoid reclosing onto fault, and accurately estimating the reclosing instant to provide the best reclosing system performance 
[10]-[17]. However, such studies and others did not evaluate the effect of single-pole autoreclosure operation on the DFIG performance. Also, incorporating the autoreclosure in the double-circuit transmission systems is not evaluated for the wind driven DFIG.

Reference to the simulated system shown Figure 1 and as this fault is considered as a transient fault type, the arcing element between the conductor and ground is implemented using the dynamic arc by [26];

$$
\frac{d g}{d t}=\frac{1}{\tau}\left(\frac{|i|}{\left(U_{o}+r|i|\right) l}-g\right)
$$

Where $g$ is the time dependent arc conductivity, $t$ is the time, $\tau$ is the arc time constant, $i$ is the arc current, $l$ is the arc length, $r$ is the arc resistance per unit length, and $U_{o}$ is the arc voltage per unit length. In order to implement the arcing fault, the dynamic arc model (10) is solved for each instantaneous arc current $i$. This solution is done with defining the arc parameters concerning the Kizilcay arc modeling that the arc time constant is $1.3 \mathrm{~ms}$, arc voltage per unit length is $12 \mathrm{~V} / \mathrm{cm}$, arc resistance per unit length is $1.3 \mathrm{~m} \Omega / \mathrm{cm}$, and arc length is $350 \mathrm{~cm}$ as defined in [10], [27], [28]. This arc implementation is suitable only for the primary arc period that has characteristics with high arcing current. However, for the secondary arc period, the arcing current is extremely reduced due the single-pole breaker opening at both terminals of the faulted phase. Although the same differential equation is used, the arc parameters are changed. However, the secondary arc period does not affect the dynamic performance of the DFIG and the DFIG sees the system as it is in normal operation with missing single-phase in the double circuit transmission system. Accordingly, this secondary arcing period is not represented in the simulation benchmark. Only, the period of 0.24 sec observed in the simulation in [10], [26], [27] is considered as the time sufficient for extinguishing the secondary arc period. Then, the system can restore reclosing the isolated circuit to the normal operation. The tower resistance is considered $12 \Omega$ that is added in series with the arcing model.

\section{RESULTS AND ANALYSIS}

Integrating the models of the DFIG considering the data given in the Appendix, MLI, SVC, dynamic arc model, and double transmission line is accomplished using the Matlab/Simulink program. Accordingly, the simulation-based evaluation of incorporating the MLI within the DFIG instead of one of the conventional converters is evaluated with the single-pole autoreclosure as follows.

\subsection{Arcing Fault Evaluation}

First, the dynamic arc characteristics are evaluated as shown in Figure 4. Referring to the system shown in Figure 1(a), the fault occurred at the middle of a circuit in the double-circuit transmission line where the fault instant is $1 \mathrm{~ms}$. Accordingly, the fault current is suddenly increased as shown in Figure 4(a) while the fault is reduced at $1.202 \mathrm{~s}$ when a single-pole of the breaker $\mathrm{CB}_{\mathrm{A} 2}$ operates to isolate the fault from the grid side. Then, the fault is fully isolated when the single-pole of breaker $\mathrm{CB}_{\mathrm{B} 2}$ operates at $1.304 \mathrm{~s}$ at the DFIG side. Accordingly, there are two different arcing fault periods as depicted by the dynamic arc characteristics in Figure 4(b). This performance confirms the bilateral interaction between the arc model and the power system.

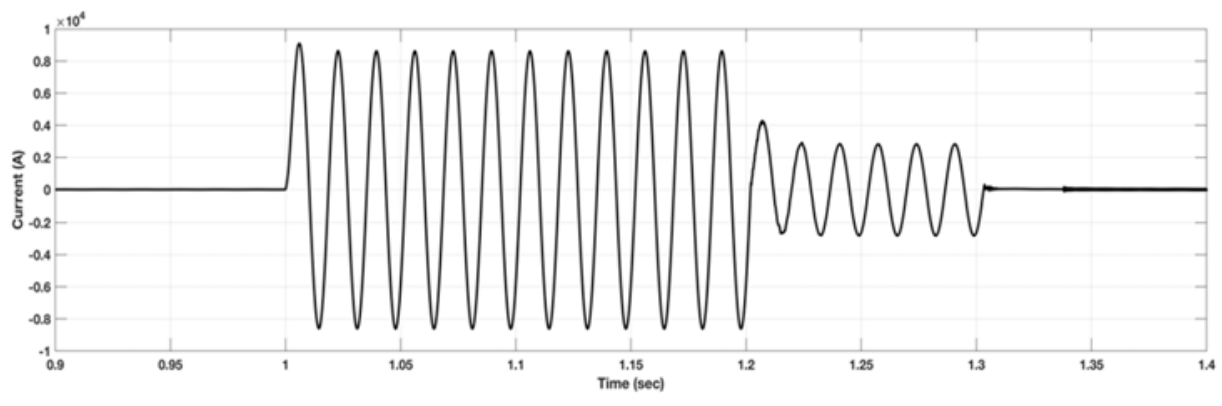

(a) Fault current 


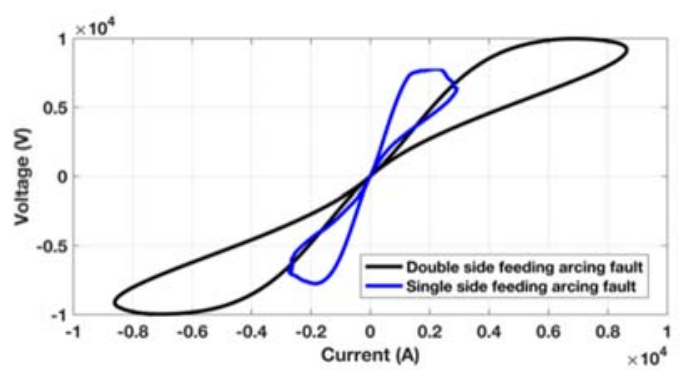

(b) Dynamic arcing characteristics

(c)

Figure 4. Arcing fault case at the middle of a circuit in double-circuit transmission system

\subsection{Evaluation of DFIG integrated MLI}

As aforementioned, the autoreclosure scenario is that the fault occurred at $1 \mathrm{~s}$, a single-pole of breakers $\mathrm{CB}_{\mathrm{A} 2}$ and $\mathrm{CB}_{\mathrm{B} 2}$ respectively opened at $1.202 \mathrm{~s}$ and $1.304 \mathrm{~s}$ to isolate the faulted phase, then the secondary arcing fault period was extinguished at $1.54 \mathrm{~s}$, and finally the opened single-poles of the breakers $\mathrm{CB}_{\mathrm{A} 2}$ and $\mathrm{CB}_{\mathrm{B} 2}$ respectively closed at $1.55 \mathrm{~s}$ and $1.65 \mathrm{~s}$ in order to restore the system normal operation. Accordingly, the interaction of the DFIG with the power system transient due to autoreclosure operation is evaluated as shown in Figure 5. In Figure 5(a), the fault from $1 \mathrm{~s}$ to $1.304 \mathrm{~s}$ period produced a slight effect although the fault current is high. This is because the transformer delta/star connection opens the zerosequence loop and accordingly the fault current distribution is changed to be as phase-to-phase fault with lower current amplitudes as depicted in Figure 5(b). Figure 5(c) shows the DFIG power where there is a power swing started just after the fault clearance at $1.304 \mathrm{~s}$. This power swing affects the current flow in which there is an oscillation in the current envelope as depicted in Figure 5(b). After the system restoration of the normal operation at 1.65 , the power and currents are directed to the normal operation. In the voltage waveforms in Figure 5(a), there are transient at instant $1.55 \mathrm{~s}$ that was due to closing the breaker $\mathrm{CB}_{\mathrm{A} 2}$ as the first step to connect the isolated circuit in the double circuit transmission system. These travelling waves can be reduced by controlling the breaker switching time. Figure 5(d) shows the dc voltage across the capacitor in between the two converters. The voltage behavior has slight transients due to the autoreclosure operation.

The performance of the MLI under the previous autoreclosure scenario is observed via the line-toline voltage depicted in Figure 5(e). It could be noticed here that the ratio of the dc voltages between the main stage and auxiliary stages are done using the HFT concept [25]. The line-to-line voltage is obviously nine levels as stated before. The MLI is successfully integrated with the DFIG. That behavior shown in Figure 5 confirms autoreclosure ride-through capability of the DFIG using the nine levels hybrid MLI.

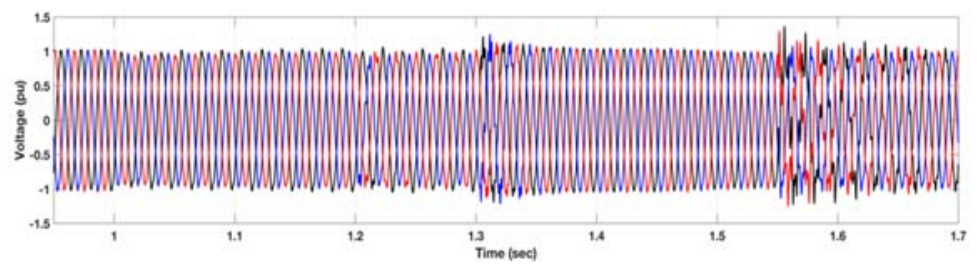

(a) 3-phase voltages at PCC

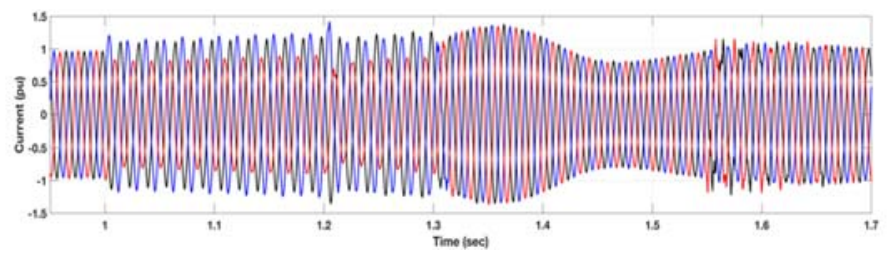

(b) 3-phase currents at PCC

Int J Pow Elec \& Dri Syst, Vol. 10, No. 1, March 2019 : $454-462$ 


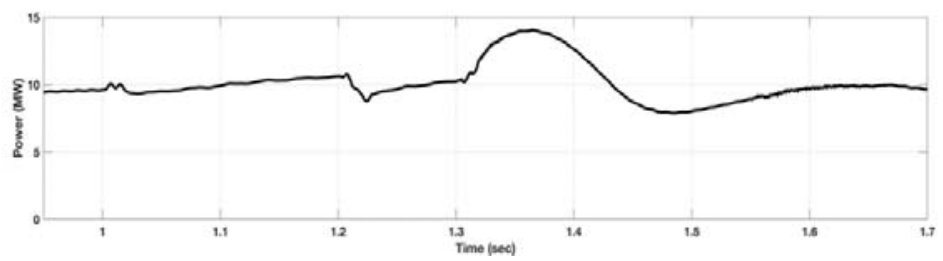

(c) Generator active power

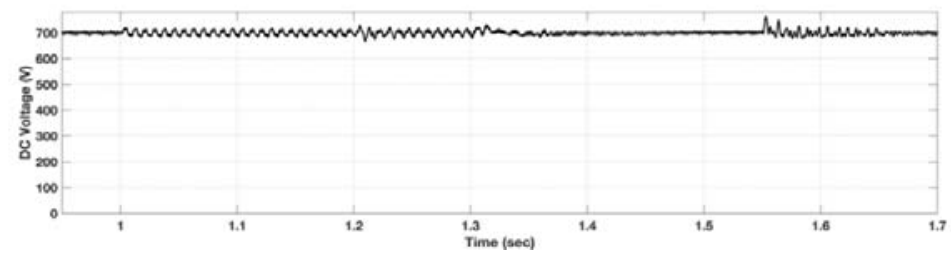

(d) $3 \mathrm{~V}_{\mathrm{dc}}$ voltage

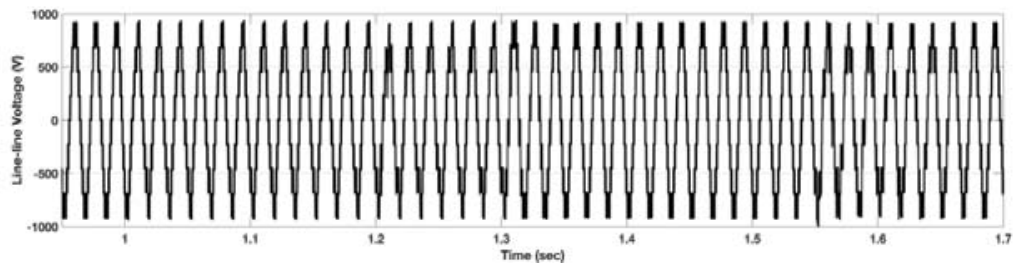

(e) MLI output ac voltage

Figure 5. (a) 3-phase voltages at PCC, (b) 3-phase currents at PCC, (c) Generator active power, (d) $3 \mathrm{~V}_{\mathrm{dc}}$ voltage, (e) MLI output ac voltage

\section{CONCLUSIONS}

The hybrid multi-level inverter has been designed and incorporated in the DFIG instead of the conventional converter at the grid side. This DFIG integrated MLI has been done for the first time. The designed MLI has been nine levels that facilitated the DFIG performance with the single-pole autoreclosure operation. The arcing fault was modeled using the Kizilcay dynamic arc model. This fault was happened in the double-circuit transmission systems. The provided results confirmed that the DFIG integrated MLI enhanced the single-pole autoreclosure ride through capability.

\section{ACKNOWLEDGEMENTS}

This work was supported by the research project grant number 5582-438-1, Scientific Research Deanship, Taif University, KSA.

\section{REFERENCES}

[1] T. Burton, D. Sharpe, N. Jenkins and E. Bossanyi, "Wind Energy Handbook. 2nd Edition”, John Wiley \& Sons, United Kingdom, 2011.

[2] G. Abad, J. Lopez, M. A. Rodriguez, L. Marroyo and G. Iwanski, "Doubly Fed Induction Machine", John Wiley \& Sons, Hoboken, New Jersey, 2011.

[3] S. M. Muyeen, J. Tamura, T. Murata, "Stability Augmentation of a Grid-connected Wind Farm", Springer-Verlag, London, 2009.

[4] J. F. Manwell, J. G. McGowan and A. L. Rogers, "Wind Energy Explained theory, design, and application", John Wiley \& Sons, England, 2002.

[5] M. Tsili and S. Papathanassiou, "A review of grid code technical requirements for wind farms," IET Renewable Power Generation, vol.3, no.3, pp. 308-332, Sep. 2009. 
[6] M. Mohsenia, S. M. Islam, "Review of international grid codes for wind power integration: Diversity, technology and a case for global standard," Renewable and Sustainable Energy Reviews, vol. 16, no. 6, pp. 3876-3890, Aug. 2012.

[7] M. Altin, O. Goksu, R. Teodorescu, P. Rodriguez, B.-B. Jensen and L. Helle, "Overview of recent grid codes for wind power integration," $12^{\text {th }}$ International Conference on Optimization of Electrical and Electronic Equipment (OPTIM), Basov, pp. 1152-1160, May 2010.

[8] F. Iov, A. Hansen, P. Soerensen and N. Cutululis, "Mapping of grid faults and grid codes," Technical report of the research project 'Grid fault and design basis for wind turbine', RISO National Laboratory, Denmark, 2007.

[9] J. Schlabbach, "Low voltage fault ride through criteria for grid connection of wind turbine generators," $5^{\text {th }}$ International Conference on European Electricity Market (EEM), Lisboa, pp. 1 - 4, 28-30 May 2008.

[10] N. I. Elkalashy, H. A. Darwish, A.-M. I. Taalab, M. A. Izzularab "An adaptive single pole autoreclosure based on zero sequence power" Electric power systems research, vol. 77, no. 5, pp. 438-446, April 2007.

[11] T. A. Kawady, N. I. Elkalashy, A. Elsayed and A.-M. I. Taalab "Arcing Fault Identification Using Combined Gabor Transform-Neural Network for Transmission Lines" International Journal of Electrical Power and Energy Systems, Vol. 61, pp. 248-258, Oct. 2014.

[12] M. Jannati, B. Vahidi, S. H. Hosseinian, S. M. Ahadi "A novel approach to adaptive single-phase auto-reclosing scheme for EHV transmission lines" International Journal of Electrical Power and Energy Systems, vol. 33, no. 3, pp. 639-646, March 2011.

[13] F. D. Zahlay and K. S. Rama Rao "Neuro-Prony and Taguchi's Methodology-Based Adaptive Autoreclosure Scheme for Electric Transmission Systems" IEEE Transactions on Power Delivery, vol. 27, no. 2, pp. 575 - 582, April 2012.

[14] M. Khodadadi, M. R. Noori, S. M. Shahrtash, "A Noncommunication Adaptive Single-Pole Autoreclosure Scheme Based on the ACUSUM Algorithm" IEEE Transactions on Power Delivery, vol. 28, no. 4, pp. 2526 - 2533, Oct. 2013.

[15] M. Nagpal, S.-H. Manuel, B. E. Bell, R. P. Barone, Ch. Henville, D. Ghangass, "Field Verification of Secondary Arc Extinction Logic", IEEE Transactions on Power Delivery, vol. 31, no. 4, pp. 1864-1872, Aug. 2016.

[16] D. Lin, H. Wang, D. Lin, B. He, "An Adaptive Reclosure Scheme for Parallel Transmission Lines with Shunt Reactors", IEEE Transactions on Power Delivery, vol. 30, no. 6, pp. 2581-2589, Dec. 2015.

[17] A. R. Adly, R. A. El-Sehiemy, A. Y. Abdelaziz, S. A. Kotb "An Accurate Technique for Discrimination between Transient and Permanent Faults in Transmission Networks" Electric Power Components and Systems, vol. 45, no. 4, pp. 366-381, 2017.

[18] I. Colak, E. Kabalci, and R. Bayindir "Review of multilevel voltage source inverter topologies and control schemes," Energy Conversion and Management 2011, 52, pp. 1114-1128, 2011.

[19] S. Debnath, J. Qin, B. Bahrani, M. Saeedifard, and P. Barbosa, "Operation, Control, and Applications of the Modular Multilevel Converter: A Review," IEEE Transactions on Power Electronics, Vol. 30, No. 1, pp. $37-53,2015$.

[20] Ayong Hiendro, "Multiple Switching Patterns for SHEPWM Inverters Using Differential Evolution Algorithms," International Journal of Power Electronics and Drive System (IJPEDS), Vol.1, No.2, 94-103, December 2011.

[21] S. Ouni, M. R. Zolghadri, M. Khodabandeh, M. Shahbazi, J. Rodríguez, H. Oraee, P. Lezana, and A. U. Schmeisser, "Improvement of Post-Fault Performance of a Cascaded H-bridge Multilevel Inverter," IEEE Transactions on Industrial Electronics, Vol. 64, No. 4, pp: 2779 - 2788, 2017.

[22] Wahidah Abd Halim, Tengku Noor Ariana Tengku Azam, Komathi Applasamy, Auzani Jidin, "Selective Harmonic Elimination Based on Newton-raphson Method for Cascaded H-bridge Multilevel Inverter," International Journal of Power Electronics and Drive System (IJPEDS), Vol. 8, No. 3, 1193-1202, September 2017.

[23] S. Mekhilef, M. N. Abdul Kadir, and Z. Salam, "Digital Control of Three Phase Three-Stage Hybrid Multilevel Inverter," IEEE Transactions on Industrial Informatics, vol. 9, pp. 719-727, 2013.

[24] S. Mekhilef and M. N. A. Kadir, "Novel Vector Control Method for Three-Stage Hybrid Cascaded Multilevel Inverter," IEEE Transactions on Industrial Electronics, vol. 58, pp. 1339-1349, 2011.

[25] Mahrous Ahmed, Essam Hendawi, Mohamed K. Metwaly," Single Phase Asymmetrical Cascaded MLI with Extreme Output Voltage Levels to Switch Ratio ", International Journal of Power Electronics and Drive Systems (IJPEDS), Vol.9 No. 2, pp 712-721, June 2018.

[26] M. Kizilcay and T. Pniok, "Digital Simulation of Fault Arcs in Power systems," Europe Transaction on Electrical Power System, ETEP, vol. 4, no. 3, pp. 55-59, Jan./Feb. 1991.

[27] H. Darwish and N. Elkalashy "Universal Arc Representation Using EMTP," IEEE Trans. on Power Delivery, Vol. 2, no. 2, pp 774-779, April 2005.

[28] N. W. Miller; J. J. Sanchez-Gasca; W. W. Price; R. W. Delmerico , "Dynamic modeling of GE 1.5 and 3.6 MW wind turbine-generators for stability simulations," IEEE Power Engineering Society General Meeting (IEEE Cat. No.03CH37491), Vol. 3, pp. 1977 - 1983, 2003. 